ENCYCLOPEDDIE Encyclopédie berbère

BERBERE

$10 \mid 1991$

10 | Beni Isguen - Bouzeis

\title{
Bou Taleb
}

C. El Briga

\section{OpenEdition}

Journals

Édition électronique

URL : http://journals.openedition.org/encyclopedieberbere/1795

DOI : 10.4000/encyclopedieberbere. 1795

ISSN : 2262-7197

\section{Éditeur}

Peeters Publishers

\section{Édition imprimée}

Date de publication : 1 décembre 1991

Pagination : 1577-1579

ISBN : 2-85744-549-0

ISSN : 1015-7344

Référence électronique

C. El Briga, « Bou Taleb », Encyclopédie berbère [En ligne], 10 | 1991, document B95, mis en ligne le 01 juin 2013, consulté le 25 septembre 2020. URL : http://journals.openedition.org/encyclopedieberbere/ 1795 ; DOI : https://doi.org/10.4000/encyclopedieberbere.1795

Ce document a été généré automatiquement le 25 septembre 2020

(c) Tous droits réservés 


\section{Bou Taleb}

\section{El Briga}

Le petit massif du Bou Taleb (point culminant le Djebel Afghane, $1890 \mathrm{~m}$ ) fait partie de la chaîne des Monts du Hodna qui assure la liaison orographique entre l'Atlas tellien (Monts des Bibans) et l'Aurès. Cette chaîne est formée, du nord-ouest au sud-est, par les Monts des Ouennougha, les Monts des Maadid, le Bou Taleb, les Monts des Ouled Sellem et le Bélezma. Le massif du Bou Taleb, d'environ $30 \mathrm{~km}$ de long et de 10 de large, ne possède pas dans cet ensemble une originalité particulière sur le plan structurel ou morphologique. Comme les autres massifs, il présente un relief dissymétrique ; l'abrupt tourné vers le sud domine la plaine du Hodna. La structure est simple, c'est un anticlinal de roches crétacées et jurassiques, mais des crêtes dolomitiques du Lias ont été dégagées par l'érosion et se dressent au-dessus des marnes crétacées qui assuraient la couverture aujourd'hui largement disséquée. Le versant nord est moins accidenté et a conservé une couverture rocheuse peu propice à l'agriculture. Au contraire le versant sud, bien qu'abrupt et moins arrosé, offre de plus grandes facilités aux agriculteurs. Aussi est-il plus peuplé et ses habitants étendent leurs cultures sur le Djer, glacis incliné vers la cuvette du Hodna arrosé par des séguia alimentées par des sources ou des dérivations de la Soubella. Le Bou Taleb possède encore d'importants boisements de chênes verts et de pins d'Alep; les cèdres occupent les versants du Djebel Afghane audessus de $1500 \mathrm{~m}$. 
Le massif du Bou Taleb entouré de son fossatum (d'après J. Baradez) et les principales voies de transhumance (d'après J. Despois). En hachuré, les zones berbérophones, extension vers l'ouest des dialectes chaouiia.

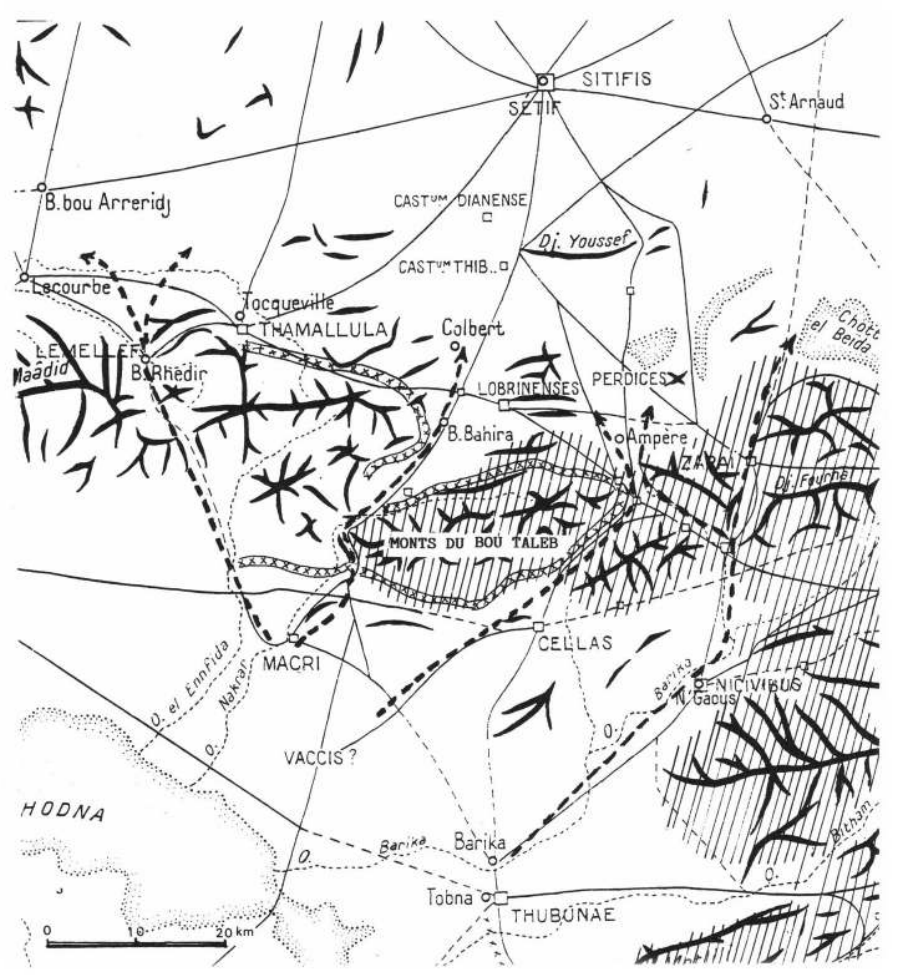

2 Le massif du Bou Taleb est séparé de celui des Maadid par les gorges de l'oued Soubella, qui prend ensuite le nom de Nekhar puis Maghra. Ces gorges pittoresques, étroites et profondes, servent également de limite occidentale aux parlers berbères du groupe chaouïa. Ainsi le Bou Taleb constitue l'avancée extrême vers l'ouest des parlers chaouïas qui sont ici séparés du groupe kabyle par un isthme arabophone étroit de 70 $\mathrm{km}$ dont l'axe serait matérialisé par les villes de Sétif, Bordj-bou-Arréridj et M'sila.

Dans l'antiquité le massif du Bou Taleb présentait une autre originalité, celle d'être presque entièrement entouré d'un fossé doublé d'un mur et contrôlé, d'après $\mathrm{J}$. Baradez, par de nombreux ouvrages militaires, tours de gué et castella. Ce dispositif est continu au sud, à l'est et au nord, seul la vallée de la Soubella en semble dépourvue. Pour J. Baradez il s'agit d'un fossatum appelé localement Khret Faraoun (le sillon du Pharaon) de caractère militaire comparable à celui qui existe beaucoup plus au sud. Les recherches plus récentes de J. Soyer permettent de penser que ce fossatum n'était pas limité au seul massif du Bou Taleb et qu'il se poursuivait à l'ouest, au moins jusqu'au sud de la ville romaine de Thamallula (ex Tocqueville), entourant peut-être la totalité des Monts du Hodna. Mais les fonctions exactes d'un tel ouvrage demeurent mystérieuses, seule est manifeste la volonté d'entourer le massif par une ligne de défense continue. On peut penser que, comme en d'autres secteurs du limes, le fossatum du Bou Taleb avait pour fonction de canaliser pour les contrôler, les déplacements des transhumants vers les deux passages que sont la vallée de la Soubella à l'ouest et celle de l'oued Seggane à l'est ; mais ces deux voies sont les seules possibles et ce sont celles qu'empruntent aujourd'hui les troupeaux venus du sud; cela se fait si naturellement qu'on ne voit pas la nécessité d'entourer le massif par un ouvrage continu. On peut croire aussi que ce fossé était destiné à contenir la population du massif et l'empêchait 
de piller les terres cultivées, mais la population de ce petit massif n'a jamais été assez nombreuse pour constituer une pareille menace contre les centres et les cultures de la plaine de Sétif au nord ou du Hodna au sud.

\section{BIBLIOGRAPHIE}

Baradez J., Fossatum Africae, recherches aériennes sur l'organisation des confins sahariens à l'époque romaine, Paris, A.M.G., 1949.

Depois J., Le Hodna, Paris, P.U.F., 1953.

Despois J. et Raynal H., Géographie de l'Afrique du Nord-Ouest, Paris, Payot, 1967.

Soyer J., « Les centuriations romaines en Algérie orientale », Antiquités africaines, t. 10, 1976, p. 107-180.

INDEX

Mots-clés : Géographie, Linguistique 